\title{
Writing with the waters. An interview with Triestine author Claudio Magris
}

\author{
by Maurizio Tani
}

Let us start with your penultimate novel, Alla cieca, inside which you recall several figures from classical mythology, such as Medea, Jason, and the Argonauts. They are tokens of ancient Mediterranean mythology, specifically Hellenic, who have never stopped stimulating modern writers. This is true of Nordic writers too. Halldor Laxness masterpiece, Free Men although usually translated as Independent People contains recurrent references to the Argonauts and Jason. The protagonist, Bjartur the proud farmer, is depicted as though he were trying to colonise the barren Icelandic tundra, sailing desperate in the infinite emptiness of the islands interiors. He resembles a Jason of the land, who is at times an errant shepherd of Asia, whilst other times he is a horseman lost in the Euro-Asian steppes somewhat in between tenger (sky in Mongol) and tenger (sea in Hungarian). In your scholarly pieces on Scandinavian literature and art, you did notice yourself the widespread reception of Jason in Iceland, most notably in the oeuvres of Thorvaldsen. Why do you think that the modern Nordic cultures, and above all the Icelandic one, are still drawn to Hellenic, Mediterranean mythology?

I believe that the discovery of the myth can take place in two main ways, one negative and another positive. Negative is the passive, irrational attitude before the myth; to consider the truth that the myth reveals as immutable, like the essence of a nation or of a civilisation that claim to be eternal and that can be used, as done by fascism, against change, reason, and humanism. The great Austrian writer Hermann Broch, and with him several other writers and scholars, wrote momentous pages on this attitude. However, the myth has any authenticity whatsoever if and only if the myth is understood qua deep structure, i.e. as a sort of anthropological backbone of civilisation that, as it has been said, tells what has never happened and yet always happens. To take it literally means to become enslaved to it. Instead, the myth must be read through the lenses of reason, with an Enlightenment-like mind, which allows for its poetry to be grasped. The myth says that Aphrodite was born from the foam of the sea and the genitals of Uranus; it is something that has never happened, but that in some way always happens, for the myth hints at the relationship that unites the sea, the infinite, and the erotic. The myth, as Valry has said, is that which happens solely in the word; it is a tale, it possesses the metaphorical and fantastic truth of tales. Thus, the myth expresses collective feelings and drives, sinking its roots within the collective unconscious, and thus explains the interest of modern culture in the mythical. And above all in the Mediterranean mythology, since the Mediterranean has been the crib of an entire civilisation and therefore of a field of possible imagination, hence of the various ways in which meaning can be attributed to life and to death (the myth has a lot to do with death).

One of the great cultural events in history has been the encounter between the 
Mediterranean and the Nordic mythologies, both of which provide answers to the great problems of the origin, the end, and time. These answers being poetic answers; they are neither true nor false in the way religious and scientific ones are, but poetic answers, which are true because groundless and devoid of any pretension to be grounded upon some reality or immediate truth. The myth then is a highly ambiguous word that can be used to mean many different things. One can speak of the myth of revolution like an idea-force, or like a lie, and so on. We can only grasp the myth in its poetry if we look at it with irony, i.e. by acknowledging its constitutive mixture of passion and fable.

As regards my short novel Illazioni su una sciabola, it is the first novel that I have written, on a topic that had been fascinating me since childhood, when I found myself in the town of Udine occupied by the Germans and by the Cossacks. I offered the topic to Borges, but he declined and encouraged me to write the novel. It displays a classic case of mythical interpretation. It centres upon some poor Cossacks, whom the Germans had recruited amongst exiled whites and prisoners of war captured after the invasion of USSR They had been promised a Cossack homeland, which in the original plans would have had to be situated somewhere in Soviet Union. However, as the war went on and, thanks to God, as the Germans position started dwindling, this Cossack homeland began to shift more and more to the West on the map, until, for a few months during the last winter of the war, it came to be identified with an area in Carnia, in Friuli [north-eastern Italy]. This homeland was a mixture of falsehood and authenticity. It was authentic because the Cossacks did in fact have a right to a land of their own. It was false because they were going to take it away from others, but above all because there is nothing more false, artificial, than a Cossack homeland in Friuli. This way, an authentic historical and human passion [the desire for a homeland] was being turned into some bizarre equestrian circus. All this was happening also because the Cossacks themselves, beginning with their leader Krasnov, were not able to look with irony at their own destiny, hence the relativity of every passion of ours, of every truth of ours, which are always historical, relative, and never absolute. He who believes to be authentic, is most false; we can be authentic only if we know how difficult it is to be so and how one can merely aspire to approximate authenticity. Krasnov is at the same time tragically serious and tragically comical, because of the gap between the role that he believes to be carrying outhe dreams of great battles and performs a grandiose Cossack ceremony in a dismal hotel of a small village, surrounded by pens and hensand the role that he actually carries outno great military operation, but marginal and despicable mopping-up actions. In this, he becomes a symbol of us all, because each and every one of us, in his own way, falls victim to the same irony of fate, i.e. the large gap between what we think we are and do and what we truly are and do.

In my previous question I mentioned Bjartur the proud farmer and novel Jason, who sometimes looks like a misplaced Euro-Asiatic horseman. In his misplacement, he certainly resembles Pyotr Nikolayevich Krasnov in Alla cieca, leader of a Cossack army bound to be exterminated. Does a tragic, common destiny exist, which encompasses the traditional divisions between North and South, East and West, 
I think there is no single common destiny. There is the infinite variety of existence and of human history, within which there are some essential chords that, in eminently diverse forms, recur incessantly, such as love, loyalty, war, peace, escape, desertion.

Then, which meaning and importance do you attribute to words like East and West, North and South?

Woe to turning East and West into myths. They are correct words if they are meant to designate certain civilisations, without implying any value judgment. From our point of view, we can legitimately say that the Chinese civilisation is an eastern civilisation. Unfortunately, however, there has been a violent and unjust tendency in Europe, and above all in Middle Europe, to despise the East, to consider the East, the Orient, as something inferior, promiscuous, dark, negative, barbaric. In my native Trieste this tendency could be perceived in the widespread prejudices against the Slavic world. But nearly every country has its own East to reject, to repudiate. Obviously, this is a most serious mistake, an injustice. Also, the term Balkans, which indicates simply a geographic reality, has often become a disparaging word. And, with this, its precise use as definiens has been lost. The prince Metternich said scornfully that beyond the Rennweg, a great artery that cuts through Vienna, began the Balkans, a term that for him signalled disorder, dirt, and so on. Some years ago, in Ulm, just some hundred kilometres West of Vienna, people said with contempt that in Neu-Ulm, on the other side of the Danube, inhabited prevalently by immigrants, the Balkans began, a term that also in this case was not a kind word. As for North and South, one should be equally cautious vis--vis any false and cheap mythical fascination with these terms. Today they work mostly as metaphors for a contrast between the economically and politically richer worldcivilised and so onand the more economically and socially backward one. In this perspective, there is perhaps a literature of the North of the world and one of the South of the world; the latter being capable of the most remarkable poetic efficacy and of major ethical intensity, as well as archaic and mythical. It is sufficient to mention the great South American literary tradition; moreover, an exemplary great author of an ideal South of the world is the sublime Chinese writer Mo Yan.

Let us consider in more detail your own homeland, Trieste and Friuli. It appears to have played a major role in the recent history of Italian culture (e.g. Italo Svevo aka Hector Aron Schmitz, Pier Paolo Pasolini, Graziadio Isaia Ascoli, Umberto Saba). One could think that this frontier region has a special gift, at least in comparison with many other regions that compose Italy today. Is then being a frontier region advantageous or disadvantageous?

Trieste and Friuli are not one single land by any stretch of imagination. They are two very dissimilar parts of an internally diverse region and it is often this diversity that paralyses the region itself, stemming not just from petty conflicts and rivalries, but 
from actual, deep-seated differences too. My name reveals my Friuli origin on my fathers sidemy grandfather moved to Trieste, while his brothers remained to work on the fields in Friuli. My mothers family is from Dalmatia, her family being Venetian and, in its oldest ancestry, Greek, belonging to the lower ranks of aristocracy. It is on her side that I can retrieve the typical character of Trieste, which is intimately linked to multiethnic Middle-Europe. On Trieste and the issues you raise with your question I wrote in a book co-authored with Angelo Ara, a talented historian and dear friend who died last year. The book is entitled Trieste. Unidentit di frontiera. In it we analyse the topic of the frontier qua identity or obsession of identity. As for advantages and disadvantages, the frontier is sometimes a bridge and sometimes a barrier; it can stimulate dialogue with the other or extinguish it. Milosz, the Nobellaureate Polish writer, tells that in Vilnius (the capital of Lithuania) there were some great Jewish poets who wrote in Yiddish, the language of the eastern Jews, and that they met in a caf a few hundred meters from the one in which Milosz met his friends and colleagues. Yet he learnt of their existence and of their greatness only twenty years later, in Paris, reading their poetries translated into French. The two-, threehundred meters between the two cafs had needed a long journey in time and space in order to be overcome.

Often, the frontier is like the Great Wall of China. It is the obsession to situate someone or something on the other side. Literature, amongst other things, is also an itinerary that one undertakes hoping to get rid of this myth of the other side, in order to understand that everyone is found, at times, on the one side and, at times, on the other side of the frontier, and in order to understand than everyone is the Other. Trieste literature is rich of such testimonies, e.g. the novels by Enzo Bettiza and Fulvio Tomizza, in which there are characters who are considered Italians by the Slavs and Slavs by the Italians. Sometimes, the frontier allows for the discovery of plural identities, i.e. the realisation that one is part also of another world. Such is the case, for instance, of Marisa Madieri, who was my wife (she died twelve years ago). In her novel Verde acqua she tells the history of her Italian family, who were forced to leave Fiume, today Rijeka, quickly after the Second World War. The Slavs, after enduring the violence caused by the Italians and fascism, were now savouring their own rejoinder and their vendetta, which, like every vendetta, was indiscriminate. Marisa Madieri tells how her family and she, then a child, abandoned Fiume, her native town, and lived for years a hard life in a refugee camp. In those trying years Marisa Madieri discovers also her familys Hungarian, hence Slavic, origins, which had been blocked out for the sake of Italian nationalism and in response to the persecution suffered as Italians. This way she discovers that she is on the other side as well; she is part, in some measure, of the world that threatens her. She thus discovers the meaning of plural identities, being Italian but, so to speak, Italian with a special gift. The frontier gives one the sense of identity as estrangement, i.e. feeling oneself on the other side, as recounted by Biagio Marin, the great Grado poet and friend of mine. In 1915, speaking with the university rector in Vienna, the young Biagio Marin declared himself to be passionately Italian and willing to destroy Austria. He was an Italian irredentist that wanted Trieste, then belonging to Austria, to become part of Italy. Yet, some time later, after enlisting as a volunteer in the 
Italian army fighting against Austria, he was unbecomingly humiliated by an Italian officer, to whom he said: Captain, you are a villain; we Austrians are accustomed to different manners.

How much do you feel yourself to be a frontier person? And what type of frontier is yours; a border, a trench?

Certainly it was fundamental for me, even before I became aware of it, my being born and growing up in Trieste. This city of frontier was itself a frontier, torn inside by invisible borders, and after the Second World War it became a no mans land for many years. When I was a child (I was born in 1939) the nearest frontier was no ordinary frontier, but a frontier that divided sharply the world itself in two parts. It was the Iron Curtain. I saw that frontier on the Carso, whenever I went to take a walk and play. And behind that frontier there was a disowned, immense, threatening world; the world of the East under the dominion of Stalin. It was a world in which nobody was allowed to go, because the frontier was opened many years later. It was the East the East often ignored, rejected, feared, despised. Still, every country has its East to reject. At the same time, behind the very same frontier, there was a world that I knew very well, because there were lands that had been part of Italy until the war, after which they had been seized by Yugoslavia. I had been in those lands as a child. They were therefore familiar and known to me. In some way, I felt that behind the frontier there was something both known and unknown, which I think is most valuable for literature, insofar as literature is often a journey from the known to the unknown, but also from the unknown to the known, or an unknown which we reclaim. Even in ones own house, when walking outside a room and into another, it may come to pass that something until then familiar reveals itself to be strange or alarming; and also that something or someone that we thought different and far away is revealed instead similar and close to us.

Trieste and the Friuli are on the forefront, as they say, in several fields, e.g. technological research, global trade, international cooperation (viz. the so-called Euro-regions), linguistic policies (i.e. the promotion of Friuli language). Which role do you think Friuli will play in Italy and in Europe? What do you think of the current attempts being made to promote the study of the Friuli language? How artificial do you think them to be? Can it be useful? Why? And how would you define the Friuli and Trieste identities? How much should be preserved of them? How much has been lost, instead, during the processes of nationalisation and Italianisation of Friuli?

I am not at all certain that Trieste and Friuli are on the forefront; perhaps, in some respects, they are; but in many others they are not. Besides, I am in no position to be able to predict what role either Trieste or Friuli can have in the future. The danger of frontier communities is the danger of becoming fixated upon identity, of turning identity into an obsession, of having a complex that hides uncertainty and leads to overemphasise, to show identity at all costs, to put up a scene and therefore to counterfeit it. I believe time should not be wasted on defining any identity (which, in 
any case, would be very different as the two cases are concerned). The Trieste identity is certainly not closer to the Friuli one than to that of any other region in Italy. The Trieste identity can be best expressed through the words of Scipio Slataper, who has in some way invented the literary landscape of Trieste with Il mio Carso in 1911. The first three paragraphs of this work begin with the words I would like to tell you.

Slataper would like to say that he was born on the Carso; he would like to say that he was born in Moravia; he would like to say that he was born in Croatia. Naturally it is not true. He was born in Trieste, but he expresses his desire to speak to the others, to the Italians; he too is an Italian and a few years later he will die in the Great War, for the cause of Triestes being Italian. Slataper makes the reader understand that, in order to communicate his own condition as an Italian but not completely so, somehow peculiar vis--vis the other Italians, he must rely upon that means that the Greeks regarded as typical of poets, i.e. to lie. Often lies, metaphors, are the only way to tell the truth, to tell what we are, which adventure is ones own.

An identity is lived in an authentic way if it is lived spontaneously, without reflecting upon it and without thinking too much, indeed if we forget about it, in the same way as we live without thinking about life. Every identity is complex, always racially mixed, if we go back in history and dig everyones past back to light. Moreover, any identity is never fixed, for it is always changing; Roberto Toscano wrote that identity can be filmed, because it is always in motion, but never photographed, because it is never still. It changes in time. Furthermore, one should not speak of one identity, but of several identities, because we have many identities and the national one is not the most important. There is the national identity, the cultural one, the political one, the religious one, that sexual one, and so on. I am certainly closer to a liberal democrat of Uruguay than to a fascist from Trieste. To speak about proper-to-Friuli or proper-toTrieste is always dangerous and mendacious. Thus, it is mendacious, for example, for a language to become an ideological tool, instead of simply loving and expressing oneself spontaneously in that language. Sure, the Friuli language is a language, with great possibilities and also a literary tradition, but to me it seems laughable to start teaching in the Friuli language either quantum mechanics or English, and it would be even more laughable to do the same in the Trieste dialect.

\section{What do you think of the non- and anti-Italian feelings that can be encountered often in Friuli? How do you explain it?}

These feelings are regressive and growling, resentful. The correct, true, authentic love for ones birthplace only exists when it is not placed in opposition to belonging to a broader identity. To be from Trieste (or from Milan, Napoli, etc.) does not contradict being Italian, and he who perceive the contrast is counterfeiting both identities. The current trends pushing towards micro- and local nationalisms, the growling and endogamous league-isms are condemned to asphyxia and sterility, and they falsify any true love for ones own native land. Dante had already said all this when he wrote that by drinking from the waters of river Arno he had learned to love Florence, whilst adding also that our native land is the entire world, like the fishs is the whole sea. 
This feeling of belonging to a given culture is false when turned into ideology. There may be a given culture (e.g. the Middle-European, the French, etc.) that it is assimilated, that becomes part of the inner self, without any conscious intention to do so. I am not at all sure that the Middle-European culture has influenced me more than the French; perhaps the reverse is true. But it is already a mistake to reflect upon it. Naturally, having read many of those authors, being familiar with those landscapes, loving those cities and those traditions, becomes my way of being, which is true when it is lived, false when it is theorised.

Let us abandon politics for a moment and get back to your book Alla cieca. Its protagonist seems to be the sea, water as such. It is not the familiar water of the Adriatic Sea and of the Danube, about which you have also written, but the much more perilous waters of the ocean, especially of the Atlantic Ocean off the coasts of Iceland. Why this interest in water? Is it only a matter of being born in Trieste, not until long a ago a major Mediterranean port for central Europe? It would be of great interest to know what you think, not just as a writer but also as a Germanic philologist and a student of European culture, about the organisation of human vicissitudes and the history of the European communities along hydrographical regions (e.g. Danube Europe, Baltic Europe, Atlantic Europe, Mediterranean Area). Are these notions really useful in order to describe and to understand the cultural and linguistic history of the several communities that live in the said parts of the Euro-Asian and African continents?

I distrust these formulations and names when they become simple labels. There are indeed great multiethnic and multicultural of extreme interest, like those of Danube Europe or that Baltic, which I would be happy to study, if I knew the languages necessary in order to dive into that reality.

As regards the water, the sea. Water, and in particular the sea, is an essential element in my life. The sea of Trieste, which I have loved since childhood, is the sea where my mother took me every day to dive in its waves and where, when I am in Trieste, I still bathe, every day, between the end of April and the beginning of November. The seas of water, yes, but also the seas of paper; the great literature that has told us about the sea and transformed it into the symbol of our own existence, of the adventures and of the challenges of life: Verga, Stevenson, Melville, Conrad, and so on. Also the Vikinger. The sea is like a great abandonment, a feeling of harmony with the flow of existence, in spite of its many shipwrecks, storms, and tragedies. The sea for me is the prime landscape of eros, of love, as I believe one can perceive in Alla cieca and other volumes that I have written. We, as a species, originated from the sea, millions and millions of years ago; our body is made in great part of water; we learn to swim before we learn to walk, as we spend the first part of our life inside our mothers womb. Already in the Odyssey, the greatest of all books, the sea is the fundamental landscape for the journey of life. Certainly, all this has to do with much more than simply Trieste, but for me it has nevertheless a lot to do with Trieste too, such as the 
concrete familiarity that one learns in Trieste vis--vis the seahaving relatives and friends who have spent their life on the sea, carrying home news from distant countries The sea is opening, not closing; the sea opens to the world, and gives one the sense of the vastness, but also of the unity, of life.

Why did you choose the adventurer Jorgen Jorgensen, who first and vainly tried to lead the Icelandic nation to independence, as the hero of your novel Alla cieca? Does he more than others incarnate the Homeric hero you so much admire?

If I had not met, by chance, Jorgen Jorgensen, I could not have written Alla cieca. My hero can live only by retrieving, in his delirium, a complement or a projection of himself in the figure of Jorgensen. His spirit of adventure, his love for the sea, his mixture of heroism and chicanery, truth and falsity, bewitched me. And above all the detail that he, after founding Hobart Town, was there later condemned to forced labour; as though Romulus had been forced into slavery in Rome. That truly set my imagination in motion. Still, I believe that the essential factor was another, namely the grotesque mini-revolution of Jorgen in Iceland, with its mixture of authenticity and theatricality, of true love for the Icelanders and of swindle. That mini-revolution was like a deforming and grotesque mirror that allowed meor so do I hopeto deal with passion and honesty, but without rhetoric and therefore with critical distance, the greater topic of revolution, for which another crucial character of mine lived,

Salvatore.

\section{Which relationship have you entertained with Iceland?}

I have always had a relationship of great fascination. As a boy, I read the sagas, in Italian, in German, and then in English. I read also much scaldic poetry, and various translations of the Edda and of the Edda Snorra; then I have indulged in the works of successive authors, and contemporary ones. Always Iceland has remained a country of great fascination, a sort of whiteness of my imagination. Thus I was extremely happy to be able to visit it. It is a country that, God knows why, has always been present in my mind and in my imagination.

How do you judge the renewed interest of the Italians for the Great North and for Iceland in particular? Perhaps you are aware of the success enjoyed by the books Omero nel Baltico and I Custodi del Messaggio. Dalla Commedia al cenacolo, la mappa segreta del viaggio di Dante in Islanda sulle trace del Graal.

I cannot answer this question, because I do not know well enough the phenomena to which you are referring, except for the book on Homer in the Baltic Sea. As for the title of the latter book, which I have not read, the Caretakers of the Message and then the Graal make me lose any desire to take a glance at that book. The esoteric, the faked mystery, the occult, are a cheap take on real imagination, on the true mystery of life and travelling and writing. They are mystery fit for a circus. We should never forget that in the Eleusinian mysteries the final, true revelation was the contemplation of the simple wheat. 
(English translation by Giorgio Baruchello)

Claudio Magris (b. 1939, Trieste) is an Italian scholar, translator and writer. He has been Professor of Modern German Literature at the University of Trieste since 1978. His reserach encompasses E.T.A. Hoffmann, Henrik Ibsen, Italo Svevo, Robert Musil, Hermann Hesse, Jorge Luis Borges and Danubian Literature (cfr. "Il mito Absburgico nella letteratura austriaca moderna", 1963). Water has been one of the main themes of his novels, e.g. "Danubio" (1986; "Danube"), "Un altro mare" (1991; "A different sea") and "Alla cieca" (2005,"Blindly"). He is a regular contributor to major European periodicals and newspapers. He served as Senator of the Italian Republic from 1994 to 1996 as independent. 